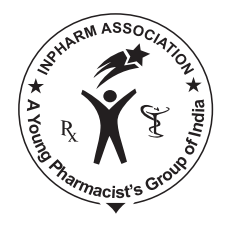

\title{
JIP
}

\section{Changes in Serum Electrolytes, Urea, and Creatinine in Aloe Vera-treated Rats}

\author{
Saka WA, Akhigbe RE, Popoola OT, Oyekunle OS \\ Department of Physiology, College of Health Sciences, Ladoke Akintola University of Technology, \\ Ogbomoso, Oyo State, Nigeria
}

Address for correspondence: Mr. Akhigbe RE; E-mail: akhigbemcroy@yahoo.com

\begin{abstract}
This study was carried out to investigate the effect of Aloe vera extract ( $\mathrm{AvE}$ ) on serum electrolytes, urea, and creatinine as indices of renal function in Sprague-Dawley rats. Twelve male Sprague-Dawley rats weighing between 80 and $130 \mathrm{~g}$ were used. Rats were divided into two groups: The control and the test groups $(n=6)$. The test group received $1 \mathrm{ml}$ of AvE daily for 28 days. Both the groups fed on standard rat chow and water ad libitum. The results showed a decrease in serum levels of sodium, and potassium, but an increase in the serum levels of bicarbonate, urea, and creatinine in the test group. The changes seen were, however, statistically insignificant, except for the serum levels of sodium and creatinine $(P<0.05)$. It is thus concluded that AvE impairs renal handling of electrolytes with consequent hyponatremia and hypercreatinemia. However, this might be of therapeutic value in conditions associated with hypernatremia.
\end{abstract}

Key words: Aloe vera, creatinine, electrolytes, kidney, urea

\section{INTRODUCTION}

Aloe vera, also known as medicinal aloe, is widely used in food products, pharmaceuticals, and cosmetics due to its therapeutic properties..$^{[1,2]}$ Its biologically active compounds include polysaccharides, mannans, lectins, chromes, anthraquinone, and anthrone derivatives..$^{[3]}$ Alloin has been reported to be the major anthraquinone of aloe exudates

\begin{tabular}{|l|l|}
\hline \multicolumn{2}{|c|}{ Access this article online } \\
\hline Quick Response Code: & \\
\hline & Website: \\
\hline & www.jyoungpharm.in \\
& DOI: \\
\hline
\end{tabular}

and gels $^{[4]}$ and it is characterized as the c-glycoside of aloe-emodin. ${ }^{[5]}$

Aloe has been reported to have hypoglycemic properties, ${ }^{[6,7]}$ normalize plasma lipid status, ${ }^{[8]}$ and laxative properties. ${ }^{[9]}$ It has also been associated with the increase in the alcohol oxidation rate in rats, ${ }^{[10]}$ cytotoxicity against human breast cancer cell lines, ${ }^{[11]}$ and changes in urinary compositions. ${ }^{[12,13]}$ Its laxative property has been reported to be the major adverse effect. ${ }^{[14]}$

From literature search, although the effects of Aloe on urinary compositions and its laxative effects have been reported, no study has clearly demonstrated its influence on plasma electrolytes, urea, and creatinine in association with urinary composition changes previously reported. This study thus sought to investigate the effect of aloe 
on serum electrolytes, urea, and creatinine as indicators of renal function.

\section{MATERIALS AND METHODS}

\section{Animals}

Male Sprague-Dawley rats weighing between 80 and $130 \mathrm{~g}$ and 6-8 weeks old were used for the experiment. They were housed in standard rat cages under laboratory conditions with $12: 12 \mathrm{~h} \mathrm{light} / \mathrm{dark}$ cycle at $25^{\circ} \mathrm{C} \pm 2$. The animals were allowed to acclimatize for 2 weeks. ${ }^{[15]}$

\section{Treatment}

Animals were divided into two groups $(n=6)$; the control and test groups. The test group was treated with $1 \mathrm{ml}$ of Aloe vera juice daily for 28 days. All rats, both the control and the test groups, were fed on standard rat chow and water ad libitum.

\section{Extraction of Aloe vera}

Fresh stems of Aloe vera were washed thoroughly to get rid of all forms of debris. The leaves were then sliced longitudinally to cut open the inner part of the leaves. The gel in the leaves was scrapped into a clean bowl and blended to obtain a finer and liquefied form of the gel, the aloe juice. The juice was refrigerated below $4^{\circ} \mathrm{C}$ for preservation. ${ }^{[16]}$

\section{Blood sample collection}

After the 28 days of administration of Aloe vera juice, the blood sample from the animals were initially collected via the retro-orbital plexus, after which they were killed by cervical dislocation and more blood samples were obtained via heart puncture. The blood sample obtained from each rat was put in lithium-heparinized sample bottles. Serum was obtained by centrifuging at $3000 \mathrm{rpm}$ for $15 \mathrm{~min} .^{[17]}$

\section{Determination of serum electrolytes, urea, and creatinine}

Serum sodium and potassium levels were determined using the Flame photometry method (410 flame photometer, Chiron Diagnostics) following the manufacturer's guidelines. ${ }^{[18]}$ Serum bicarbonate, urea, and creatinine were determined using the standard assay kit following back titration, diacetyl monoxime, and alkaline picrate methods, respectively.

\section{Statistical analysis}

Data are expressed as mean \pm standard deviation (SD). The significant difference between the test group and the control group were analyzed using unpaired $t$-tests. Data were analyzed using the SPSS software (SPSS Inc., Chicago, USA). $P<0.05$ was set as the level of significance.

\section{Ethics}

All animals received humane care in compliance with the institution's guidelines and criteria for humane care as outlined in the National Institute of Health Guidelines for the care and use of Laboratory Animals.

\section{RESULTS}

The result showed a significant decrease in the serum sodium level in the test group after administration of the Aloe vera extract (AvE) as compared to the control rats $(P=0.004)$ [Figure 1]. There was a nonsignificant decrease in the potassium level in the test rats as compared to the control rats $(P=0.549)$ [Figure 2]. The serum level of bicarbonate also showed a nonsignificant increase in the test rats when compared to that of the control rats $(P=0.305)$ [Figure 3].

Similarly, there was a nonsignificant increase in the urea level in the test rats when compared to the control rats $(P=0.221)$ [Figure 4]. The serum level of creatinine showed a significant increase in the test rats when compared to the control rats $(P=0.042)$ [Figure 5].

\section{DISCUSSION}

This study aimed at investigating the effect of AvE on renal function by evaluating the serum concentrations of electrolytes, urea, and creatinine. This appears to be the first study to investigate and document changes in serum electrolytes as indices of renal function following aloe treatment in association with changes in urinary composition previously reported. The result from this study demonstrated that AvE treatment induced electrolyte

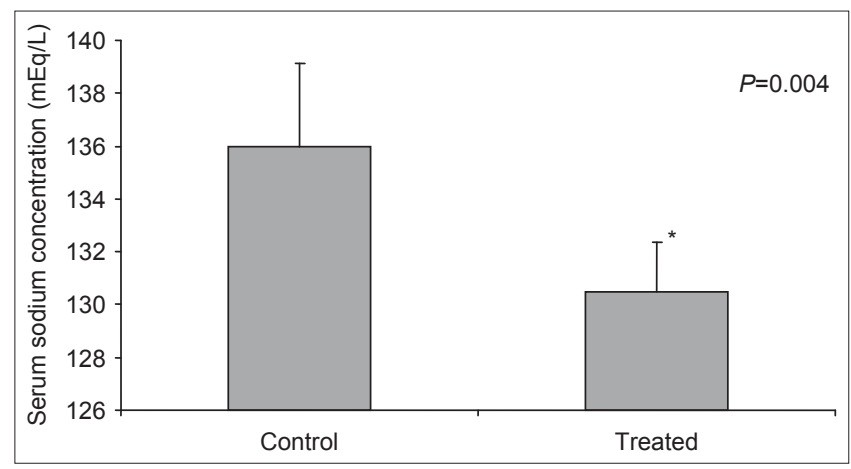

Figure 1: Effect of Aloe vera extract on serum sodium concentration $\left({ }^{\star} P<0.05\right.$ vs. control) 


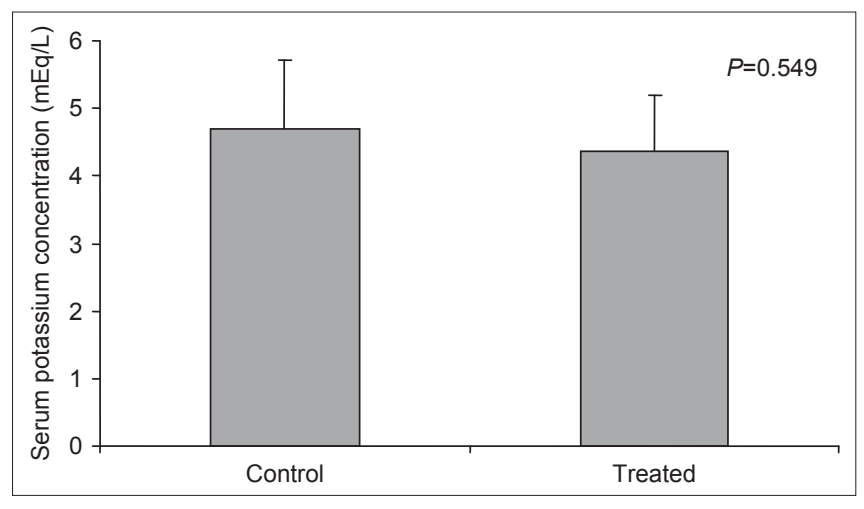

Figure 2: Effect of Aloe vera extract on serum potassium concentration

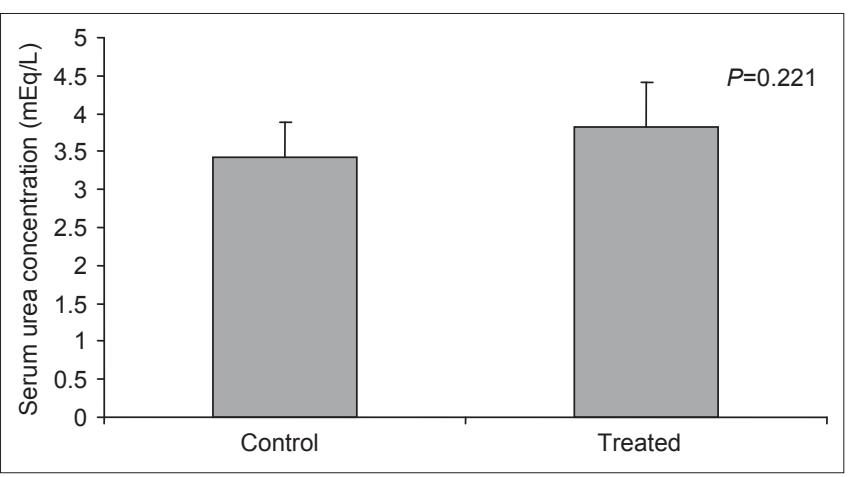

Figure 4: Effect of Aloe vera extract on serum urea concentration

imbalance in experimental animals. This is in tandem with findings of the previous studies. ${ }^{[9,12,13]}$ Sodium is the most abundant extracellular ion, and it plays an important role in muscle contraction. Similarly, potassium, an abundant intracellular ion, plays a vital role in muscle contraction. The electrolyte derangement resulting from the reduced serum level of sodium seen in this study thus provides evidence that the use of aloe could present a risk for arrhythmia, abdominal pain and cramping, and muscle weakness.

The observation that aloe induces electrolyte imbalance corroborates findings in the previous study that reported its laxative properties. ${ }^{[14]}$ It causes excess water loss accompanied by sodium loss, thus contracting the extracellular fluid with resultant electrolyte imbalance and consequent impairment of muscle contraction.

Ranganath and Gould ${ }^{[19]}$ associated reduction in sodium and potassium ions with the increased bicarbonate level. This study seems to be the first to report the effect of aloe on plasma $\mathrm{pH}$ by evaluating serum bicarbonate concentration. Although there were reductions in the serum level of sodium and potassium, and a rise in serum bicarbonate concentration, only the reduction in sodium concentration was significant $(P<0.05)$, while changes in potassium and bicarbonate ions were nonsignificant $(P>0.05)$. This shows that aloe-induced electrolyte imbalance evident by low

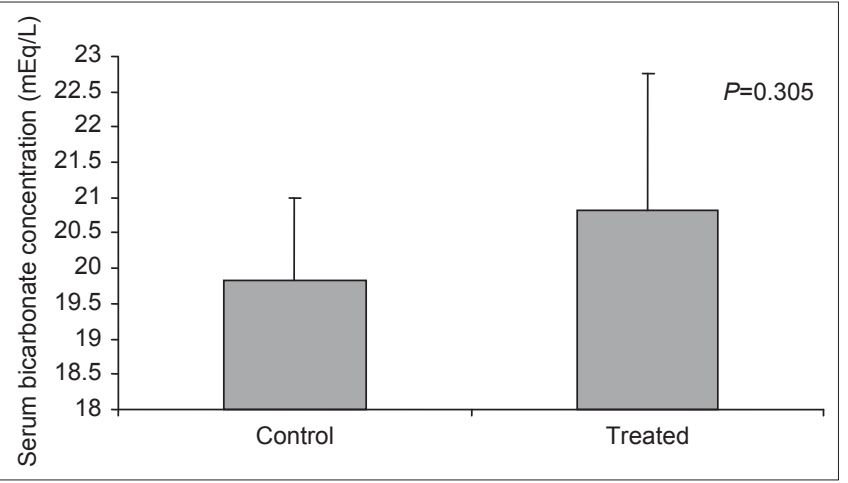

Figure 3: Effect of Aloe vera extract on serum bicarbonate concentration

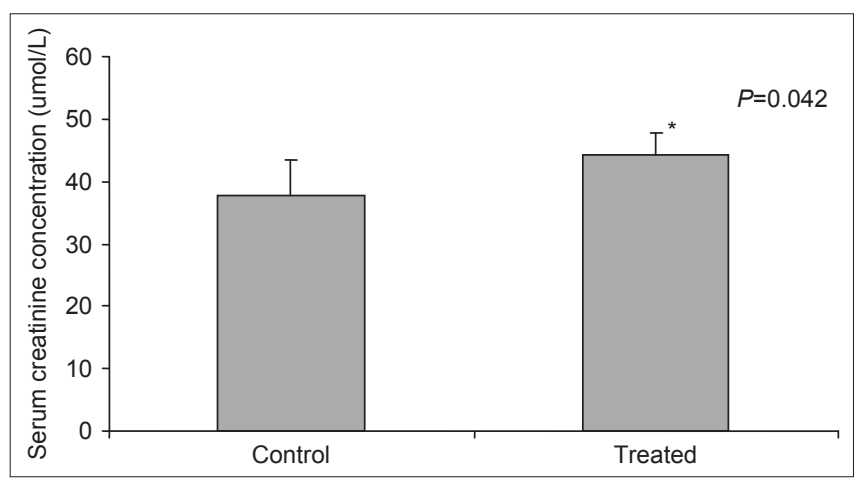

Figure 5: Effect of the Aloe vera extract on the serum creatinine concentration ( ${ }^{*} P<0.05$ vs. control)

plasma level of sodium, though significant, was not enough to cause metabolic alkalosis.

Creatinine clearance calculated from creatinine concentrations in urine and plasma samples, and the urine flow rate, as well as urea clearance, is used to determine the glomerular filtration rate of the kidneys. Although not commonly done anymore, they remain useful tests for renal function. ${ }^{[20]}$ Thus, plasma concentrations of creatinine and urea could be used as indicators of nephrotoxicity. ${ }^{[21-25]}$ Low clearance of creatinine or/and urea indicates a diminished impaired ability of the kidneys to filter these waste products from the blood and excrete them in urine. As their clearance values decrease, their blood levels increase. Hence, an abnormally elevated blood creatinine is diagnostic of impaired renal function. ${ }^{[21-25]}$

This study revealed that aloe induces a significant rise in serum creatinine. This is in consonance with the study of Avila et al. ${ }^{[2]}$ that reported the cytotoxic effect of aloe. This study suggests that aloe promotes nephrotoxicity, thus causing impaired renal function evident by an increase in serum creatinine concentration. This could also explain the electrolyte imbalance associated with the aloe use. The altered level of plasma sodium seen in aloe treatment might be as a result of sodium loss due to its cytotoxic effect. 
It is noteworthy that hyponatremia is a major challenge associated with the aloe use, however, if given with close monitoring of serum electrolytes might be beneficial in conditions associated with hypernatremia.

\section{CONCLUSION}

This study showed that oral administration of aloe is associated with renal dysfunction, evident by serum electrolyte imbalance, leading to hyponatremia and hypercreatinemia. However, this might be beneficial in conditions associated with hypernatremia.

\section{REFERENCES}

1. Davis RH, DiDonato JJ, Johnson RW, Stewart CB. Aloe vera, hydrocortisone, and sterol influence on wound tensile strength and anti-inflammation. J Am Podiatr Med Assoc 1994;84:614-21.

2. Korkina L, Suprun M, Petrova A, Mikhal'chik E, Luci A, De Luca C. The protective and healing effects of a natural antioxidant formulation based on ubiquinol and Aloe vera against dextran sulfate-induced ulcerative colitis in rats. Biofactors 2003;18:255-64.

3. Tom R. Aloes-the genus aloe. Florida, USA: CRC Press; 2004.p. 40-7.

4. Groon QJ, Reynols T. Barbaloin in aloe species. Planta Med 1987;53:345-8.

5. Reynold T. The compounds in Aloe leaf exudates: A review. Bot J Linn Soc 1985;90:157-77.

6. Chalaprawat M. The hypoglycemic effects of a Aloe vera in Thai diabetic patients. J Clin Epidemiol1997;50:S3.

7. Devaraj S, Jialal R, Jialal I. Effect of Aloe vera supplements in patients with prediabetes. FASEB J2009;23:900-7.

8. Rajasekaran S, Ravi K, Sivagnanam K. Beneficial effects of Aloe vera leaf gel extract on lipid profile status in rats with streptozotocin diabetes. Clin Exp Pharmacol Physiol 2006;33:232-7.

9. Natural Medicines Comprehensive Database. Aloe monograph. Available from: http://www.naturaldatabase.com/(S(qvu2t455cblgtk450bop1yev))/ home.aspx?cs $=$ ands $=$ ND. [Last accessed on 2009 Oct 13] .

10. Chung JH, Cheong JC, Lee JY, Roh HK, Cha YN. Acceleration of the alcohol oxidation rate in rats with aloin, a quinine derivative of Aloe. Biochem Pharmacol 1996;52:1461-8.
11. Esmat AY, Tomasetto C, Rio MC. Cytotoxicity of a natural anthraquinone (aloin) against human breast cancer cell lines with and without ErbB-2: Topoisomerase II alpha coamplification. Cancer Biol Ther 2006;5:97-103.

12. Kirdpon S, Kirdpon W, Airarat W, Thepsuthammarat K, Nanakorn S. Changes in urinary compositions among children after consuming prepared oral doses of aloe (Aloe vera Linn). J Med Assoc Thai 2006;89:199-205.

13. Kirdpon S, Kirdpon W, Airarat W, Trevanich A, Nanakorn S. Effect of aloe (Aloe vera Linn.) on healthy adult volunteers: Changes in urinary composition. J Med Assoc Thai 2006;89:S9-14.

14. Koch A. Metabolism of alloin-the influence of nutrition. J Pharm Biomed Anal 1996;14:1335-8.

15. Akhigbe RE, Olatunji LA, Soladoye AO, Oyeyipo IP. Effect of angiotensin 1-converting enzyme inhibitor, captopril, on body weight, and food and water consumption in oral contraceptive-treated rats. Am J Biochem Mol Biol 2011;1:95-100.

16. Ige SF, Akhigbe RE, Adewale AA, Badmus JA, Olaleye SB, Ajao FO, et al. Effect of Allium cepa (Onion) extract on cadmium - induced nephrotoxicity in rats. Kidney Res J 2011;1:41-47.

17. Akhigbe RE, Azeez OM, Ige SF, Oyeyipo IP, Ajao FO, Soladoye AO. Hemorheological effect of long-term administration of oral contraceptive in rats. Int J Pharmacol 2008;4:403-6.

18. Akhigbe RE, Ige SF, Afolabi AO, Oyeyipo PI, Ajao FO, Ajayi FA. Water balance and serum levels of some electrolytes in oral contraceptive-treated female wistar rats. J Med Sci 2008;8:591-4.

19. Ranganath LR, Gould SR. Postural hypotension and electrolyte disturbance in a 6 year old man. Postgrad Med J 1999;75:185-7.

20. KDOQ1 CKD Guideline. Retrieved on 2010 Aug 25.

21. Pagana KD. Mosby's manual of diagnostic and laboratory tests. St. Louis, MO: Mosby, Inc.; 1998.

22. Brenner BM, Floyd C. The kidney. $6^{\text {th }}$ ed. philadelphia, PA: W. B. Saunders Company; 1999.

23. Burtis CA, Edward RA. Tietz textbook of clinical chemistry. Philadelphia, PA: W.B. Saunders Company; 1999.

24. Wallach J. Interpretation of diagnostic tests. $7^{\text {th }}$ ed. Philadelphia: Lippincott Williams andWilkins; 2000.

25. Henry JB. Clinical diagnosis and management by laboratory methods. $20^{\text {th }} \mathrm{ed}$. Philadelphia, PA: W. B. Saunders Company; 2001.

26. Avila H, Rivero J, Herrera F, Fraile G. Cytotoxicity of a low molecular weight fraction from Aloe vera (Aloe barbadensis Miller) gel. Toxicon 1997;35:1423-30.

How to cite this article: Saka WA, Akhigbe RE, Popoola OT, Oyekunle OS. Changes in serum electrolytes, urea, and creatinine in Aloe vera-treated rats. J Young Pharmacists 2012;4:78-81.

Source of Support: Nil, Conflict of Interest: None declared.

Announcement

\section{Android App}

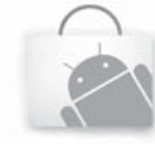

Download

Android application

A free application to browse and search the journal's content is now available for Android based mobiles and devices. The application provides "Table of Contents" of the latest issues, which are stored on the device for future offline browsing. Internet connection is required to access the back issues and search facility. The application is compatible with all the versions of Android. The application can be downloaded from https:// market.android.com/details?id=comm.app.medknow. For suggestions and comments do write back to us. 